\title{
Association study of polymorphisms in FOX03, AKT1 and IGF-2R genes with human longevity in a Han Chinese population
}

\author{
Ning Li ${ }^{1,2,3, *}$, Huaichao Luo ${ }^{1,3, *}$, Xiaoqi Liu' ${ }^{1,3}$, Shi Ma ${ }^{1,3}$, He Lin ${ }^{1,3}$, Rong Chen ${ }^{1,3}$, Fang \\ Hao $^{1,3}$ and Dingding Zhang ${ }^{1,4}$ \\ ${ }^{1}$ Sichuan Provincial Key Laboratory for Human Disease Gene Study, the Institute of Laboratory Medicine, Sichuan Academy \\ of Medical Sciences and Sichuan Provincial People's Hospital, Chengdu, Sichuan, China \\ 2 Department of Immunology, Zunyi Medical College, Zunyi, Guizhou, China \\ ${ }^{3}$ Sichuan Translational Medicine Hospital, Chinese Academy of Sciences, Chengdu, Sichuan, China \\ ${ }^{4}$ Department of Health Management, Sichuan Academy of Medical Sciences and Sichuan Provincial People's Hospital, \\ Chengdu, Sichuan, China \\ * These authors have contributed equally to this work
}

Correspondence to: Dingding Zhang, email:918676628@qq.com

Keywords: human longevity, FOXO3, AKT1, IGF-2R, single nucleotide polymorphism (SNP), Gerotarget

Received: July 01,2015 Accepted: November 23, $2015 \quad$ Published: December 16, 2015

\section{ABSTRACT}

F0X03, AKT1 and IGF-2R are critical members of the insulin/IGF-1 signaling pathway. Previous studies showed that polymorphisms (SNPs) in FOXO3, AKT1 and IGF-2R were associated with human longevity in Caucasian population. However, the association of these SNPs in different ethnic groups is often inconsistent. Here, we investigated the association of genetic variants in three genes with human longevity in Han Chinese population. Twelve SNPs from FOX03, AKT1 and IGF-2R were selected and genotyped in 1202 long-lived individuals (nonagenarians and centenarians) and younger individuals. Rs9486902 of FOXO3 was found to be associated with human longevity in both genders combined in this study (allelic $\mathbf{P}=\mathbf{0 . 0 0 2}$, corrected $\mathbf{P}=$ 0.024). The other eleven SNPs were not significantly associated with human longevity in Han Chinese population. The haplotypes TTCTT, CCTTC and CTCCT of FOXO3 as well as GGTCGG and GGTCAG of AKT1 were shown to have a significant difference between case and control $\left(P=0.006,2.78 \times 10^{-5}, 4.68 \times 10^{-6}, 0.003,0.005\right.$, respectively). The estimated prevalence of diabetes and prediabetes in long-lived individuals was significantly lower than in common adult populations $\left(P=0.001,2.3 \times 10^{-26}\right)$ .Therefore, the search for longevity-associated genes provides the identification of new potential targets beneficial for the treatment of diabetes.

\section{INTRODUCTION}

The problem of aging population is known as one of the severest problems in developed and developing countries. In 2014, it is estimated that the number of elders (65 years old and over) was two hundred million in China. This figure will be three hundred million in 2025, and is still rising. The majority of age-related chronic diseases will afflict elders, such as type 2 diabetes, hypertension, coronary heart disease, cancer, etc. Previously, Terry et al. [1] reported that long-lived individuals (nonagenarians and centenarians) will delay or escape from age-related disease. However, the exact molecular basis of this phenomenon is scarcely known. Thus, identification of longevity related gene/loci is not only defining the underlying mechanisms of human longevity, but also to provide insights into the study of pathogenesis of agerelated disease in the future.

In the last few years, several studies have shown that many SNPs in genes from the insulin/IGF-1 signaling pathway were significantly associated with human longevity. For instance, FOXO3, AKT1 [2], FOXOIA [3], INS1 [4], INSR [5], etc. Willcox et al. [6] showed that the polymorphisms of the $\mathrm{FOXO} 3$ gene (rs2802292, rs2764264, rs1327795) were significantly different between long-lived individuals and controls with $P$ value of $0.0002,0.0006,0.0001$ respectively, suggesting that these variations were more likely to be susceptibility polymorphism of human longevity in a Japanese population. In addition, a considerable number of 
replicated studies were frequently reported. These studies include rs2802292 in FOXO3 (Li et al. 2009; Anselmi et al. 2009; Soerensen et al. 2010) [7-9], rs 2764264 in FOXO3 (Anselmi et al. 2009; Soerensen et al. 2010) $[8,9]$, rs13217795 in FOXO3 (Soerensen et al. 2010) [9], rs4946936 in FOXO3 (Flachsbart et al. 2013; Li et al. 2009) [7, 10], rs7762395 in FOXO3(Soerensen et al. 2010; Nygaard et al. 2014) [9, 11], rs1935949 in FOXO3 (Pawlikowska et al. 2009) [12], rs479744 in FOXO3 (Li et al. 2009; Soerensen et al. 2010; Flachsbart et al. 2009) [7, $9,13]$. However, it is unclear whether these loci recently identified in Japanese and Europeans exert a similar effect on human longevity in a Han Chinese population in the region of Sichuan. Li et al identified that genetic variants in $\mathrm{FOXO3}$ are significantly associated with human longevity in the Han Chinese population. Then, Zeng et al also confirmed the joint effects of the genotypes of FOXO3 and FOXO1A genes on human longevity [7, 14]. FOXO3 and FOXO1A are critical downstream molecules of $A K T 1$ gene [15]. Thus, we hypothesized that similar to $F O X O 3, A K T 1$ gene also possibly exerted effects on human longevity. Pawlikowska et al. [12] reported that the polymorphism of the AKT1 gene (rs3803304) has been significantly associated with human longevity in a meta-analysis across the three cohorts that consist of the cardiovascular Health study, the study of Osteoporotic Fractures and Ashkenazi Jewish Centenarians. In contrast, Nygaard et al. [16] showed that rs3803304 in the AKT1 gene was found not to be associated with human longevity in Danish and German long-lived individuals. Remarkably, these results present a paradox. In addition, Yousin Suh et al. [17] found that genetic variants in the human $I G F-1 R$ that result in altered IGF signaling pathway increase the susceptibility of human longevity. Soerensen et al. [18] demonstrated that SNP rs9456497 in the $I G F-2 R$ was significantly associated with human longevity in a Danish population, composed of 1083 long-lived individuals and 736 middle aged controls. However, this result has not been replicated by other cohorts. Meanwhile, the association between $A K T 1$ and $I G F-2 R$ with longevity has not been investigated in the Han Chinese. In the present study, we first investigated whether genetic variants in $A K T 1$ and $I G F-2 R$ genes are associated with longevity in a Han Chinese population.

Functional studies showed that $\mathrm{FOXO3}$ was involved in insulin resistance, several kinds of cancer and Type 2 diabetes [19]. FOXO3 was also important for the onset of diabetic cardiomyopathy and associated with hemoglobin A1c level and fasting plasma insulin [19, 20]. Although Soerensen et al reported that genetic variants in $\mathrm{FOXO3}$ were not significantly associated with selfreported diabetes in oldest-old Danes, the $\mathrm{FOXO3}$ protein has a wide array of downstream targets, which themselves affect a wide range of cellular and physiological processes [21]. Thus, its molecular mechanism still remains uncertain. Considering the fact that gender and ethnic population have effects on the human longevity, gender stratification and the classification of lineages of longlived individuals were necessary. In the present study, first, we analyzed Y chromosome haplogroups lineage distribution of long-lived individuals from a Han Chinese population in the region of Sichuan. Second, we examined the relationship between the 12 SNPs of FOXO3, AKT1 and $I G F-2 R$ with human longevity in a mainland Han Chinese population. Third, we compared the prevalence of diabetes and prediabetes of long-lived individuals in our study with a common adult population reported by $\mathrm{Xu}$ et al. [22]. We demonstrated that rs9486902 in FOXO3 gene is associated with human longevity in both genders, and the estimated prevalence of diabetes and prediabetes were significantly lower in long-lived individuals than in common adult population in this Han Chinese population.

\section{RESULTS}

\section{Population characteristics}

In this study, long-lived individuals and the younger control individuals were recruited from the region of Sichuan in the southwest of China. According to $\mathrm{Y}$ chromosome haplogroups lineage distribution[23], the region of Sichuan includes $\mathrm{Y}$ chromosome haplogroup $\mathrm{N}^{*}$ 8.8\%,O3-M122 80\%. Long-lived individuals underwent a standard set of laboratory tests that included measurements of hemoglobin A1c levels to assess the control situation of blood glucose levels (Tables 8, 9). The younger controls were not diabetes susceptible populations. Thus, hemoglobin A1c level was not tested in the younger control population.

\section{Genotype association analysis}

Rs9486902 in the FOXO3 gene was shown to be significantly associated with human longevity in the present study population with genotype frequencies of long-lived individuals and of younger controls $(P=0.008$, Table 2), but after bonferroni correction, the significant associations no longer existed (corrected $P=0.096$, Table 2). To further evaluate the association between $\mathrm{FOXO3}$, $A K T 1$ and $I G F-2 R$ with longevity, we applied four different genetic models. Rs9486902 showed highly significant association in Addictive 2 and Dominant models $(P=$ $0.003, \mathrm{OR}=0.55,95 \% \mathrm{CI} 0.82-0.38 ; P=0.002, \mathrm{OR}=0.55$, 95\%CI 0.81-0.37, Table 4). Rs9400239 showed borderline significant association in Addictive 1 and Recessive models $(P=0.04, \mathrm{OR}=0.66,95 \% \mathrm{CI} 0.98-0.44 ; P=0.05$, $\mathrm{OR}=0.68,95 \%$ CI $0.82-1.27$, Table 4 ). For the multiple correction, the $P$-value for significant observation should be $0.05 /(12$ SNP x 4 models $)=0.001$, because 4 statistical models were applied. As a result, none of twelve SNPs 
Table 1:The characteristics of long-lived individuals and younger individuals

\begin{tabular}{|l|l|l|}
\hline & Case $(\mathbf{n}=\mathbf{5 7 6})$ & Control $(\boldsymbol{n}=\mathbf{6 2 6})$ \\
\hline Gender(male/female) & $221 / 355$ & $282 / 344$ \\
\hline Female (\%) & 61.6 & 55.0 \\
\hline Mean age(age) & $92.8 \pm 2.6$ & $34.1 \pm 4.1$ \\
\hline Age range(age) & $90-109$ & $20-38$ \\
\hline
\end{tabular}

a The age when the cases and controls were recruited, \pm : Standard deviation

Table 2: Genotype analyses of the 12 SNPs on the FOXO3, $A K T 1$ and $I G F-2 R$ in long-lived individuals and younger individuals

\begin{tabular}{|c|c|c|c|c|c|c|}
\hline Gene & SNP & Genotype & Case n (\%) & Control n (\%) & $P$ & $\begin{array}{l}\text { Corrected } \\
P^{a}\end{array}$ \\
\hline FOXO3 & rs13217795 & $\mathrm{CC} / \mathrm{CT} / \mathrm{TT}$ & $63(11.0) / 224(38.9) / 286(49.7)$ & $54(8.6) / 237(37.9) / 323(51.6)$ & 0.39 & \\
\hline FOXO3 & rs2464264 & GG/AG/AA & $62(10.8) / 231(40.1) / 282(49.0)$ & $53(8.4) / 244(39.0) / 319(51.0)$ & 0.38 & \\
\hline FOXO3 & rs9400239 & $\mathrm{TT} / \mathrm{CT} / \mathrm{CC}$ & $67(11.6) / 229(39.8) / 279(48.4)$ & $52(8.3) / 245(39.1) / 326(52.1)$ & 0.13 & \\
\hline $\mathrm{FOXO3}$ & rs1935949 & AA AG GG & $59(10.2) / 217(37.7) / 299(51.9)$ & $51(8.1) / 234(37.4) / 340(54.3)$ & 0.41 & \\
\hline $\mathrm{FOXO3}$ & rs9486902 & $\mathrm{TT} / \mathrm{CT} / \mathrm{CC}$ & $1(0.1) / 72(12.5) / 501(87.0)$ & $0 / 47(7.5) / 578(92.3)$ & 0.008 & 0.096 \\
\hline AKT1 & rs3803304 & $\mathrm{CC} / \mathrm{CG} / \mathrm{GG}$ & $5(0.8) / 82(14.2) / 486(84.4)$ & $7(1.1) / 107(17.1) / 500(79.9)$ & 0.30 & \\
\hline AKT1 & rs2494731 & $\mathrm{GG} / \mathrm{CG} / \mathrm{CC}$ & $63(10.9) / 277(48.1) / 236(41.0)$ & $82(13.1) / 268(42.8) / 273(43.6)$ & 0.18 & \\
\hline AKT1 & rs2494732 & $\mathrm{TT} / \mathrm{CT} / \mathrm{CC}$ & $38(6.6) / 223(38.7) / 314(54.5)$ & $55(8.8) / 229(36.6) / 339(54.2)$ & 0.33 & \\
\hline AKT1 & rs2498796 & $\mathrm{CC} / \mathrm{CT} / \mathrm{TT}$ & $73(12.7) / 277(48.1) / 225(39.1)$ & $96(15.3) / 278(44.4) / 249(39.8)$ & 0.30 & \\
\hline AKT1 & rs2494738 & GG/AG/AA & $118(20.5) / 289(50.2) / 165(28.6)$ & $145(23.2) / 308(49.2) / 169(27.0)$ & 0.51 & \\
\hline AKT1 & rs1130214 & TT/GT/GG & $9(1.5) / 83(14.4) / 478(83.0)$ & $6(0.8) / 99(15.8) 509(81.3)$ & 0.51 & \\
\hline$I G F-2 R$ & rs9456497 & GG/AG/AA & $133(23.1) / 291(50.5) / 152(26.4)$ & $144(23.0) / 322(51.4) / 157(25.1)$ & 0.89 & \\
\hline
\end{tabular}

${ }^{\text {a }}$ Corrected $P, P$ value after correction for multiple testing $(P \times 12)$.

Table 3: Single nucleotide polymorphisms associated with human longevity

\begin{tabular}{|c|c|c|c|c|c|c|c|c|}
\hline Gene & $\begin{array}{l}\text { SNP } \\
\text { (Minor allele) }\end{array}$ & Chr. & $\operatorname{Position}(\mathbf{b p})^{\mathrm{a}}$ & $\begin{array}{l}P \text {-HWE } \\
\text { (case/control) }\end{array}$ & $\begin{array}{l}\text { MAF }^{\mathrm{d}} \\
\text { (case/ } \\
\text { control) }\end{array}$ & $\begin{array}{l}\text { Allelic } \\
P^{\mathbf{b}}\end{array}$ & $\begin{array}{l}\text { Corrected } \\
P^{c}\end{array}$ & $\begin{array}{l}\text { ORf } \\
(95 \% \text { CI })^{g}\end{array}$ \\
\hline FOXO3 & rs13217795(T) & 6 & 108974098 & $0.06 / 0.27$ & $0.31 / 0.28$ & 0.18 & 2.1 & $0.89(1.1-0.74)$ \\
\hline FOXO3 & rs 2464264(C) & 6 & 108934461 & $0.16 / 0.52$ & $0.31 / 0.28$ & 0.19 & 2.2 & $0.89(1.1-0.74)$ \\
\hline FOXO3 & rs 9400239(C) & 6 & 108977663 & $0.06 / 0.53$ & $0.32 / 0.28$ & 0.051 & 0.61 & $0.84(1.0-0.70)$ \\
\hline FOXO3 & rs $1935949(\mathrm{C})$ & 6 & 108999287 & $0.04 / 0.23$ & $0.29 / 0.27$ & 0.21 & 2.5 & $0.89(1.1-0.75)$ \\
\hline $\mathrm{FOXO3}$ & rs $9486902(\mathrm{C})$ & 6 & 108878052 & $0.34 / 0.33$ & $0.06 / 0.04$ & 0.002 & 0.024 & $0.56(0.81-0.38)$ \\
\hline$A K T 1$ & rs 3803304(C) & 14 & 105239146 & $0.46 / 0.64$ & $0.08 / 0.1$ & 0.15 & 1.7 & $1.2(1.6-0.93)$ \\
\hline$A K T 1$ & rs 2494731(C) & 14 & 105237680 & $0.17 / 0.21$ & $0.35 / 0.35$ & 0.85 & 10 & $0.98(1.2-0.83)$ \\
\hline$A K T 1$ & rs 2494732(T) & 14 & 105239192 & $0.85 / 0.07$ & $0.26 / 0.27$ & 0.57 & 6.8 & $1.1(1.3-0.88)$ \\
\hline$A K T 1$ & rs 2498796(C) & 14 & 105243220 & $0.39 / 0.21$ & $0.37 / 0.38$ & 0.64 & 7.7 & $1.0(1.2-0.88)$ \\
\hline$A K T 1$ & rs $2494738(\mathrm{G})$ & 14 & 105246686 & $0.68 / 0.84$ & $0.46 / 0.48$ & 0.33 & 4 & $1.1(1.3-0.92)$ \\
\hline$A K T 1$ & rs $1130214(\mathrm{~T})$ & 14 & 105259734 & $0.02 / 0.63$ & $0.09 / 0.09$ & 0.86 & 10 & $1.0(1.4-0.77)$ \\
\hline$I G F-2 R$ & rs $9456497(\mathrm{~A})$ & 6 & 160443428 & $0.78 / 0.39$ & $0.48 / 0.49$ & 0.17 & 2.0 & $1.1(1.3-0.95)$ \\
\hline
\end{tabular}

a Position(bp), Genomic positions are according to NCBI build 37;

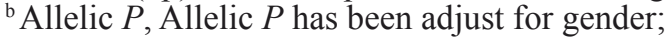

${ }^{\mathrm{c}}$ Corrected $P, P$ value after correction for multiple testing $(P \times 12)$.

${ }^{\mathrm{d}} \mathrm{MAF}$, minor allele frequency;

${ }^{\text {e }} P$-HWE, $P$-value from Hardy-Weinberg Equilibrium test;

${ }^{\mathrm{f}} \mathrm{OR}$, odds ratio;

${ }^{\mathrm{g}} \mathrm{CI}$, confidence interval. 
Table 4: Genotype analysis of 12 SNP by four genetic models (Additive1 model, Additive1 model, Dominant model, Recessive model)

\begin{tabular}{|c|c|c|c|c|c|c|c|c|}
\hline \multirow{2}{*}{$\begin{array}{l}\text { SNP ID } \\
\text { (minor allele) }\end{array}$} & \multicolumn{2}{|c|}{ Additive 1 } & \multicolumn{2}{|c|}{\begin{tabular}{|l|} 
Additive 2 \\
\end{tabular}} & \multicolumn{2}{|c|}{ Dominant } & \multicolumn{2}{|c|}{ Recessive } \\
\hline & $P^{a}$ & $\mathrm{OR}^{\mathrm{b}}(95 \% \mathrm{CI})^{\mathrm{c}}$ & $P^{a}$ & $\mathrm{OR}^{\mathrm{b}}(95 \% \mathrm{CI})^{\mathrm{c}}$ & $P^{a}$ & $\mathrm{OR}^{\mathrm{b}}(95 \% \mathrm{CI})^{\mathrm{c}}$ & $P^{a}$ & $\mathrm{OR}^{\mathrm{b}}(95 \% \mathrm{CI})^{\mathrm{c}}$ \\
\hline rs13217795 & 0.16 & $0.75(1.12-0.50)$ & 0.61 & $0.94(1.20-0.74)$ & 0.35 & $0.90(1.13-0.71)$ & 0.18 & $0.77(0.65-1.25)$ \\
\hline rs2764264 & 0.17 & $0.76(1.13-0.51)$ & 0.57 & $0.93(1.19-0.73)$ & 0.34 & $0.90(1.12-0.71)$ & 0.20 & $0.78(0.77-1.21)$ \\
\hline rs9400239 & 0.04 & $0.66(0.98-0.44)$ & 0.46 & $0.91(1.16-0.72)$ & 0.18 & $0.86(1.07-0.68)$ & 0.05 & $0.68(0.82-1.27)$ \\
\hline rs1935949 & 0.17 & $0.75(1.13-0.50)$ & 0.67 & $0.95(1.21-0.75)$ & 0.40 & $0.91(1.14-0.72)$ & 0.19 & $0.77(0.83-1.58)$ \\
\hline rs9486902 & 1.00 & & 0.003 & $0.55(0.82-0.38)$ & 0.002 & $0.55(0.81-0.37)$ & 1.00 & \\
\hline rs3803304 & 0.68 & $1.28(4.07-0.40)$ & 0.15 & $1.26(1.72-0.92)$ & 0.14 & $1.26(1.71-0.93)$ & 0.73 & $1.23(0.77-1.21)$ \\
\hline rs2494731 & 0.56 & $1.12(1.62-0.77)$ & 0.16 & $0.84(1.07-0.66)$ & 0.33 & $0.89(1.12-0.71)$ & 0.27 & $1.22(1.73-0.86)$ \\
\hline rs2494732 & 0.23 & $1.32(2.05-0.845)$ & 0.66 & $0.95(1.21-0.75)$ & 1.00 & $1.00(1.26-0.80)$ & 0.18 & $1.34(2.06-0.87)$ \\
\hline rs2498796 & 0.35 & $1.18(1.69-0.83)$ & 0.47 & $0.91(1.17-0.71)$ & 0.74 & $0.97(1.22-0.77)$ & 0.20 & $0.96(1.72-0.89)$ \\
\hline rs2494738 & 0.31 & $1.18(1.64-0.86)$ & 0.81 & $1.03(1.35-0.79)$ & 0.57 & $1.08(1.39-0.84)$ & 0.29 & $1.02(1.53-0.88)$ \\
\hline rs1130214 & 0.38 & $0.63(1.78-0.22)$ & 0.47 & $1.13(1.55-0.82)$ & 0.64 & $1.08(1.46-0.79)$ & 0.36 & $1.15(1.75-0.22)$ \\
\hline rs9456497 & 0.17 & $1.26(1.74-0.91)$ & 0.24 & $1.18(1.57-0.90)$ & 0.16 & $1.21(1.58-0.93)$ & 0.40 & $0.93(1.46-0.86)$ \\
\hline
\end{tabular}

${ }^{\text {a }} P, P$ has been adjust for gender;

${ }^{\mathrm{b}} \mathrm{OR}$, odds ratio;

${ }^{\mathrm{c}} \mathrm{CI}$, confidence interval;

Additive1 (AA versus BB); Additive2 (AB versus BB);

Dominant (AA+ AB versus $\mathrm{BB})$; Recessive (AA versus $\mathrm{AB}+\mathrm{BB})$

$\mathrm{A}$, minor allele; $\mathrm{B}$, major allele.

showed a significant difference between case and control after multiple testing.

\section{Allele association analysis and gender stratification}

Twelve SNPs from $F O X O 3, A K T 1$ and $I G F-2 R$ were within Hardy-Weinberg equilibrium (HWE) in both case $(P>0.01$, Table 3$)$ and control groups $(P>0.01$, Table $3)$. The minor allele frequencies (MAFs) of rs9486902 of $\mathrm{FOXO} 3$ was greater in long-lived individuals than in the younger control population $(P=0.002$, Table 3$)$. After bonferroni correction, the significant associations remained existing (corrected $P=0.024$, Table 3 ). When gender stratification is applied, in women, the MAFs of rs9486902 of $F O X O 3$ remained much higher in long-lived individuals than in the younger control population $(P=$ 0.008 , Table 5). Conversely, in men, rs9486902 did not show a statistic difference between the male subgroup ( $P$ $=0.073$, Table 5).

Whether or not gender stratification was applied, (rs13217795, rs2764264, rs9400239, rs1935949) in FOXO3, all of $A K T 1$ and rs9456497 in $I G F-2 R$ did not show significant difference in MAFs $(P=0.22-0.057$, Table 3) between case and control. Although the statistic differences didn't exist, the distribution trend of MAF of all SNPs from $\mathrm{FOXO} 3$ was higher in case than in control in both genders.

\section{Linkage disequilibrium and haplotype association analysis of $F O X O 3$ and $A K T 1$ gene}

12 SNPs were analyzed LD and divided into two blocks (block1: rs13217795, rs2764264, rs9400239, rs1935949, and rs9486902, D'>0.86, $121 \mathrm{~kb}$; block2: rs3803304, rs2494731, rs2494732, rs2498796, and rs2494738 D'>0.71, 9kb.), according to their degree of association and genetic distance. We tested the five SNPs from $\mathrm{FOXO} 3$ in this study using the program Haploview (Vision 4.2). We observed that haplotype TTCTT, CCTTC and CTCCT of $\mathrm{FOXO} 3$ were shown to have a significant difference between case and control $(\mathrm{P}=0.006, \mathrm{OR}=0.57$ $(0.38-0.86) ; 2.78 \times 10^{-5} \mathrm{OR}=8.7(2.6-29) ; 4.68 \times 10^{-6} \mathrm{OR}=23$ (3.2-1.7 E-2)

Table 6). Among them, while the haplotype TTCTT was the protective haplotype, the haplotype CCTTC and CTCCT were the risk haplotypes (Table 6). Furthermore, six SNPs of $A K T 1$ were also tested in the present study. We found that haplotype GGTCGG and GGTCAG have a significant difference between case and control $(P=0.003$, $\mathrm{OR}=1.4(1.1-1.7) ; 0.005, \mathrm{OR}=0.56(0.37-0.85)$ Table 7). Among them, while the haplotype GGTCAG was the protect haplotype, the haplotype GGTCGG was the risk haplotype (Table 7).

\section{DISCUSSION}

In this study, we attempt to determine whether FOXO3, AKT1 and IGF-2R are associated with human longevity in a Han Chinese population. We used a casecontrol study to examine the relationship between the 12 
Table 5: Gender effects on association of $F O X O 3, A K T 1$ and $I G F-2 R$ with longevity

\begin{tabular}{|c|c|c|c|c|c|}
\hline & & MAF & & & \\
\hline SNP & Gender & Cases/controls & OR & $95 \%$ CI & $P^{\text {a }}$ \\
\hline \multirow[t]{3}{*}{ rs13217795 } & All & $0.31 / 0.28$ & 1.13 & $0.94-1.34$ & 0.19 \\
\hline & Men & $0.32 / 0.28$ & 1.22 & $0.93-1.60$ & 0.15 \\
\hline & Women & $0.30 / 0.28$ & 1.09 & $0.86-1.37$ & 0.49 \\
\hline \multirow[t]{3}{*}{ rs2764264 } & All & $0.31 / 0.28$ & 1.13 & $0.94-1.34$ & 0.19 \\
\hline & Men & $0.32 / 0.28$ & 1.18 & $0.90-1.55$ & 0.24 \\
\hline & Women & $0.30 / 0.28$ & 1.11 & $0.88-1.40$ & 0.38 \\
\hline \multirow[t]{3}{*}{ rs3803304 } & All & $0.08 / 0.10$ & 0.80 & $0.60-1.06$ & 0.12 \\
\hline & Men & $0.08 / 0.12$ & 0.69 & $0.45-1.06$ & 0.092 \\
\hline & Women & $0.08 / 0.09$ & 0.91 & $0.62-1.33$ & 0.63 \\
\hline \multirow[t]{3}{*}{ rs9400239 } & All & $0.32 / 0.28$ & 1.19 & $1.00-1.41$ & 0.057 \\
\hline & Men & $0.33 / 0.28$ & 1.26 & $0.96-1.65$ & 0.095 \\
\hline & Women & $0.31 / 0.27$ & 1.16 & $0.92-1.47$ & 0.20 \\
\hline \multirow[t]{3}{*}{ rs1935949 } & All & $0.29 / 0.27$ & 1.12 & $0.94-1.34$ & 0.22 \\
\hline & Men & $0.31 / 0.27$ & 1.20 & 0.91-1.59 & 0.19 \\
\hline & Women & $0.28 / 0.27$ & 1.08 & $0.86-1.37$ & 0.50 \\
\hline \multirow[t]{3}{*}{ rs9486902 } & All & $0.06 / 0.04$ & 1.76 & $1.21-2.57$ & 0.003 \\
\hline & Men & $0.07 / 0.04$ & 1.64 & $0.95-2.81$ & 0.073 \\
\hline & Women & $0.06 / 0.03$ & 2.03 & $1.19-3.46$ & 0.008 \\
\hline \multirow[t]{3}{*}{ rs2494731 } & All & $0.35 / 0.35$ & 1.01 & $0.86-1.20$ & 0.87 \\
\hline & Men & $0.35 / 0.35$ & 0.99 & $0.76-1.28$ & 0.91 \\
\hline & Women & $0.35 / 0.34$ & 1.05 & $0.84-1.30$ & 0.69 \\
\hline \multirow[t]{3}{*}{ rs2494732 } & All & $0.26 / 0.27$ & 0.94 & $0.78-1.13$ & 0.50 \\
\hline & Men & $0.27 / 0.29$ & 0.93 & $0.70-1.22$ & 0.59 \\
\hline & Women & $0.25 / 0.26$ & 0.97 & $0.76-1.23$ & 0.80 \\
\hline \multirow[t]{3}{*}{ rs2498796 } & All & $0.37 / 0.38$ & 0.96 & $0.81-1.13$ & 0.64 \\
\hline & Men & $0.37 / 0.38$ & 0.96 & $0.75-1.25$ & 0.78 \\
\hline & Women & $0.37 / 0.38$ & 0.96 & $0.77-1.20$ & 0.73 \\
\hline \multirow[t]{3}{*}{ rs2494738 } & All & $0.46 / 0.48$ & 0.92 & $0.78-1.08$ & 0.29 \\
\hline & Men & $0.46 / 0.51$ & 0.84 & $0.65-1.08$ & 0.17 \\
\hline & Women & $0.46 / 0.46$ & 0.99 & $0.80-1.22$ & 0.93 \\
\hline \multirow[t]{3}{*}{ rs1130214 } & All & $0.09 / 0.09$ & 0.98 & $0.74-1.30$ & 0.88 \\
\hline & Men & $0.08 / 0.09$ & 0.87 & $0.56-1.37$ & 0.55 \\
\hline & Women & $0.09 / 0.09$ & 1.06 & $0.73-1.53$ & 0.75 \\
\hline \multirow[t]{3}{*}{ rs9456497 } & All & $0.48 / 0.49$ & 0.98 & $0.83-1.15$ & 0.77 \\
\hline & Men & $0.46 / 0.51$ & 1.21 & $0.94-1.55$ & 0.14 \\
\hline & Women & $0.50 / 0.49$ & 0.94 & $0.76-1.16$ & 0.59 \\
\hline
\end{tabular}

${ }^{a} P, P$ has not been adjust for gender;

Table 6: FOXO3 haplotype associated with human longevity in a Han Chinese population

\begin{tabular}{|c|c|c|c|c|c|}
\hline Haplotype* & Frequency & $\begin{array}{|ll|}\begin{array}{l}\text { Case, } \\
\text { frequencies }\end{array} & \text { control } \\
\end{array}$ & Chi-square & $P$-value & OR(95\% CI) \\
\hline ССТCC & 0.671 & $0.631,0.669$ & 0.058 & 0.81 & \\
\hline СТCTT & 0.205 & $0.200,0.210$ & 0.318 & 0.57 & \\
\hline TTCTT & 0.042 & $0.031,0.054$ & 7.71 & 0.006 & $0.57(0.38-0.86)$ \\
\hline СТCТC & 0.021 & $0.016,0.025$ & 2.191 & 0.14 & \\
\hline CCTTC & 0.013 & $0.022,0.003$ & 17.561 & $2.8 \mathrm{E}-5$ & $8.7(2.6-29)$ \\
\hline CTCCT & 0.010 & $0.020,0.001$ & 20.965 & $4.7 \mathrm{E}-6$ & $23(3.2-1.7 \mathrm{E}-2)$ \\
\hline
\end{tabular}

*The haplotypes were generated from SNPs rs13217795, rs2764264, rs9400239, rs1935949, rs9486902, respectively. 
Table 7: $A K T 1$ haplotype associated with human longevity in a Han Chinese population

\begin{tabular}{|l|l|l|l|l|l|}
\hline Haplotype* & Frequency & Case, control frequencies & Chi-square & $\boldsymbol{P}$-value & OR(95\% CI) \\
\hline CGCTAG & 0.435 & $0.432,0.437$ & 0.066 & 0.80 & \\
\hline GGTCGG & 0.201 & $0.224,0.176$ & 8.644 & 0.003 & $1.4(1.1-1.7)$ \\
\hline CCCTGG & 0.078 & $0.085,0.070$ & 1.981 & 0.16 & \\
\hline CGCTGG & 0.056 & $0.049,0.063$ & 2.073 & 0.15 & \\
\hline GGCCGG & 0.043 & $0.038,0.047$ & 1.077 & 0.30 & \\
\hline GGTCAG & 0.039 & $0.029,0.051$ & 7.754 & 0.005 & $0.56(0.37-0.85)$ \\
\hline GGCCGT & 0.034 & $0.032,0.037$ & 0.568 & 0.45 & \\
\hline CGCTAT & 0.031 & $0.034,0.028$ & 0.629 & 0.43 & \\
\hline CGCCGG & 0.022 & $0.020,0.023$ & 0.235 & 0.63 & \\
\hline GGTCGT & 0.012 & $0.013,0.011$ & 0.188 & 0.67 & \\
\hline
\end{tabular}

*The haplotypes were generated from SNPs rs3803304, rs2494731, rs2494732, rs2498796, rs2494738, rs1130214.

Table 8: Comparison for prevalence of diabetes between longevity and normal people reported

\begin{tabular}{|l|l|l|l|l|l|}
\hline & People with prediabetes & Normal people & Total & $\begin{array}{l}\text { Prevalence rate } \\
(\mathbf{\%})\end{array}$ & $\boldsymbol{P}$ \\
\hline Case & 42 & 534 & 576 & 7.29 & \multirow{2}{*}{0.001} \\
\hline Control ${ }^{*}$ & 11444 & 87214 & 98658 & 11.6 & \\
\hline
\end{tabular}

*Data from Xu et al ${ }^{[18]}$.

Table 9: Comparison for prevalence of prediabetes between longevity and normal people reported

\begin{tabular}{|l|l|l|l|l|l|}
\hline & People with prediabetes & Normal people & Total & $\begin{array}{l}\text { Prevalence rate } \\
(\mathbf{\%})\end{array}$ & $\boldsymbol{P}$ \\
\hline Case & 137 & 439 & 576 & 23.78 & $2.3 \times 10-26$ \\
\hline Control* & 49428 & 49230 & 98658 & 50.1 & \\
\hline
\end{tabular}

*Data from Xu et al ${ }^{[18]}$.

SNPs of $F O X O 3, A K T 1$ and $I G F-2 R$ with human longevity in a Han Chinese population. Then we compared the prevalence of diabetes of long-lived individuals in our study with common adult population reported by $\mathrm{Xu}$ et al [22].

When comparing genotype frequencies, we found that rs9486902 in $F O X O 3$ was significantly different between the longevity group and the younger control in the present study. However, after bonferroni correction, the significant associations no longer existed, suggesting that this locus was unlikely to be associated with longevity in the present study. In the following we used different genetic models (Table 4). Rs9486902 showed highly significant association in Addictive 2 and Dominant models. Rs9400239 showed borderline significant association in Addictive 1 and Recessive models Table 4). But after the multiple testing, the significant associations no longer existed, suggesting that these loci were not associated with longevity in the present study.

When performing association studies by comparing allele frequencies between long-lived individuals and younger individuals, we found that rs9486902 in $F O X O 3$ was significantly associated with longevity in both genders combined in this study. For rs9486902, the risk allele frequency was 0.06 in the cases and 0.04 in the controls (Table 3). The T allele in rs9486902 of FOXO3 was higher in the long-lived individuals than that in the younger controls. The study results were consistent with Tan et al. [24] and Soerensen et al's report in Danish population [9]. Lineages of long-lived individuals were classified according to $\mathrm{Y}$ chromosome haplogroups lineage distribution. $\mathrm{N}^{*}$ is mainly distributed on both side of the Ural mountains, the north of the Scandinavia, the north of eastern Europe,(Russia, Finland, Hungary, Estonia, Sami etc), the southwest of China. Of note, the genetic variation of similar lineage distribution has approximate consistency. Thus, we propose a hypothesis that the principle of Y chromosome haplogroups is approximately consistent with autosomal genetic variation.

Further analysis using haploview4.2 software yielded the risk haplotype CCTTC and CTCCT of FOXO3 from five SNPs proved to be significantly different between long-lived individuals and younger controls. An individual with these risk haplotypes has 8.7-fold and 23fold increased likelihood of longevity (Table 6). The risk haplotype GGTCGG of $A K T 1$ from six SNPs conferred a 1.35-fold increased likelihood of longevity (Table 7).

Previously, willcox et al. [6] reported that the single nucleotide polymorphisms of the FOXO3 gene (rs2802292, rs2764264, rs1327795) were associated with ethnic 
Japanese, suggesting that these SNPs were potentially susceptible polymorphisms of human longevity. However, these variations were not replicated in the present study. The possible reasons as follows: first, it might be due to the genetic heterogeneity of human longevity among different populations. Willcox et al's report referred to males only. Thus, we can classify population by $\mathrm{Y}$ chromosome haplogroups lineage distribution. According to the haplogrouping and nomenclature system of The Y Chromosome Consortium (YCC), Japanese males mainly belong to haplogroups $\mathrm{C}, \mathrm{D} 2, \mathrm{D} 2 \mathrm{a} 1, \mathrm{O} 2 \mathrm{~b}^{*}, \mathrm{O} 2 \mathrm{~b} 1$, and $\mathrm{O} 3 *[23,25]$. O3* haplogroups account for only $20 \%$ in Japanese males, whereas, more than $80 \%$ of the Chinese males are O3* haplogroups. Second, these SNPs might be small genetic effect sizes to human longevity in a Han Chinese population. Third, it might be the mean age of 97.9 in willcox et al's report, however, we have only 11 long-lived individuals $>100$ years, mean age 92.8 in the present study. Flachsbart et al. [13] and Deelen j et al. [26] also showed that the effects of $\mathrm{FOXO} 3$ on longevity were most prominent in centenarians. Fourth, it is possible that a small sample size generates insufficient statistical power.

A study by Terry et al. [1] reported that longlived individuals (nonagenarians and centenarians) will delay or escape from age-related disease, such as hypertension, coronary heart disease [27], cancer, and type 2 diabetes [28]. Among them, diabetes is a high risk factor for morbidity and mortality all over the world [29]. In this study, we further tested the hemoglobin A1c level in longevity group. According to the 2010 American Diabetes Association criteria [30], the estimated prevalence of diabetes in this study's longevity group was $7.29 \%$ (42 cases) and the prevalence of prediabetes was $23.78 \%$ ( 137 cases).Considering the fact that younger control individuals who we selected were mean age: 33 years, range: $20-40$ years old. These subjects were not the vulnerable group of diabetes. Thus, comparing the prevalence of diabetes in long-lived individuals with younger control individuals has no clinical significance. Referring to previous reports, $\mathrm{Xu}$ et al. [22] reported that the estimated prevalence of diabetes was $11.6 \%$ in a representative population of Chinese adults and the prevalence of prediabetes was $50.1 \%$. Because the same sampling methods, detecting instrument, and diagnostic criteria were used in the 2 investigations, suggesting that the 2 investigations may be comparable. we compared our study of long-lived individuals with the result described by $\mathrm{Xu}$ et al. [22].The estimated prevalence of diabetes and prediabetes of long-lived individuals was significantly lower $\left(\mathrm{P}=0.001,2.3 \times 10^{-26}\right.$ using chisquare test) than common adult populations. In addition, we found that rs9486902 in FOXO3 gene is associated with human longevity in both genders in this study. The future challenge is to test whether rs9486902 in FOXO3 is involved in diabetes and increases susceptibility to diabetes and prediabetes. Therefore, the search for longevity-associated genes should lead not only to an understanding of the fundamental mechanisms of human longevity, but also to the identification of new potential targets beneficial for the treatment of diabetes. It is believed that diabetes is a complex disorder caused by the interaction of multiple genetic and environmental risk factors. Further replication studies are needed to clarify the effect of living conditions and selection pressure changes on longevity.

Recently, Pawlikowska et al. [12] showed that the polymorphisms of the $A K T 1$ gene (rs 3803304) was significantly different between human longevity and controls in Ashkenazi Jewish Centenarians (adjusted $P=$ 0.043). However, Nygaard et al. [16] showed that AKT1 is unlikely associated with human longevity in German and Danish cohorts. Consistent with results in German and Danish populations, we did not find that rs3803304 in $A K T 1$ gene was associated with human longevity in a Han Chinese population. However, we did not confirm AKT1 as a human longevity gene in populations of a Han Chinese, because our selection of SNPs in $A K T 1$ is not complete. Nojima et al. [31] reported that Haploinsufficiency of $A K T 1$ prolongs the lifespan of mice, therefore, further studies are need to confirm that $A K T 1$ is associated with human longevity. Rs3803304 in AKT1 located in an intron, 70 bp away from a exon-intron boundary and in an area of high-predicted regulatory potential [12, 32], a $\mathrm{CpG}$ island is also found here, RNA signal at this intronl exon border encompasses rs 3803304 . It is possible that rs3803304 disrupts an RNA regulatory mechanism. It might be a candidate regulatory for influencing RNA splicing by microRNA, siRNA or IncRNA. The future challenge is to investigate whether this SNP rs3803304 also pose effects on gene expression. First, cloning this locus and transfect fibroblast $[33,34]$. Second, to investigate whether this SNP also pose effects on DNMT1 (DNA methyltransferase 1) [35], leading to epigenetic changes. It was previously shown that $I G F-2 R$ gene was significantly associated with human hepatic carcinoma [36]. A study composed of 1089 long-lived individuals and 736 younger controls demonstrated that rs 9456497 in $I G F-2 R$ was significantly associated with human longevity in Danish subjects [18]. However, this variation was not replicated in our study, suggesting that this locus/gene was not significantly associated with human longevity in Han Chinese population in the region of Sichuan.

In summary, we genotyped 12 SNPs from $\mathrm{FOXO}$, $A K T 1$ and $I G F-2 R$ gene in a Han Chinese population composed of 576 long-lived individuals and 626 younger controls. Our results showed one SNP (rs9486902 in FOXO3) was significantly associated with human longevity in both genders combined in this study. The six SNPs in $A K T 1$ gene and rs9456497 in $I G F-2 R$ gene are not significantly associated with human longevity in this study. This is the first investigation to analyze a possible association between $A K T 1$ and $I G F-2 R$, respectively, with 
human longevity in Han Chinese population in Sichuan region. Our results suggest that $A K T 1$ and $I G F-2 R$ are not universally human longevity genes. The estimated prevalence of diabetes and prediabetes of long-lived individuals were significantly lower than common adult population in Han Chinese population in Sichuan region.

\section{MATERIALS AND METHODS}

\section{Study subjects}

The studied population included 576 long-lived individuals (nonagenarians and centenarians) (range 90108 years, mean age 92.3 years, women proportion of $61.6 \%$ in all case). The younger control population were 626 unrelated individuals (range 20-40 years, mean age 32 years, women proportion of $55.0 \%$ in all control) (Table1). The procedures were approved by the Institutional Review Boards of the Sichuan Academy of Medical Sciences \& Sichuan Provincial People's Hospital. All individuals gave written informed consent to the study. Diagnosis of diabetes and prediabetes was based on the 2010 American Diabetes Association criteria. The basic information about long-lived individuals and younger control individuals is listed in Table 1.

\section{SNPs selection and genotyping}

Based on comprehensive literature/data base searches in different candidate longevity genes, we have selected longevity related gene/loci in this study. According to the HapMap Phase II+III (Feb.2009) of CHB database(Han Chinese in Beijing, China), the SNPs rs13217795, rs2764264, rs9400239, rs1935949, and rs9486902 were selected for FOXO3, the SNPs rs3803304 ,rs2494731, rs2494732, rs2498796, rs2494738, rs1130214 for $A K T 1$, the SNP rs9456497 for $I G F-2 R$." [6, 9, 16, 18, 24] (Table 2). DNA was extracted from peripheral blood leukocytes, using serial phenol/chloroform extraction and ethanol precipitation. Genotyping of the Han Chinese population was performed using the dye terminator-based SNaPshot method (Applied Biosystems, Foster City, CA). The SNP analysis was performed on the ABI 3130XL genetic analyzer (Applied Biosystems). All of the SNPs reported in this study had a genotyping success rate 98 percent and accuracy assessed by random genotyping of 15 percent of the samples in the subject group.

\section{Hemoglobin A1c measurement}

Whole blood was collected in EDTA-treated tubes, and the concentration of hemoglobin A1c level was determined by high-performance liquid chromatography
(HPLC) using the VARIANT II Hemoglobin Testing System (Bio-Rad Laboratories) at the central laboratory in Sichuan Academy of Medical Sciences and Sichuan Provincial People's Hospital. According to the 2010 American Diabetes Association criteria, diabetes was defined as HbA1c concentration of $6.5 \%$ or more. Prediabetes or categories of increased risk of diabetes were defined as $\mathrm{HbA} 1 \mathrm{c}$ concentrations between $5.7 \%$ and $6.4 \%$ in participants without a prior diabetes diagnosis.

\section{Statistical methods.}

The Hardy-Weinberg equilibrium (HWE) for 12 SNPs between the case and control was assessed by the $\chi 2$ test. The $\mathrm{P}$ values of the SNPs were calculated by an additive model. Differences in allele and genotype distribution between cases (long-lived individuals) and controls (younger population) were tested using logistic regression with adjustment for gender. The haplotype blocks, the D'values and $\mathrm{r}^{2}$ values for all pairs of SNPs were calculated by using software Haploview Vision 4.2. All statistical analyses were carried out using the software SPSS version 17.0 (SPSS Inc., Chicago, IL).In order to further investigate the association between $F O X O 3, A K T 1$ and $I G F-2 R$ with longevity, we applied four statistical models including additive 1 model, additive 2 model, dominant model and recessive model. Four statistical models were defined as $1(A A+A B)$ versus $0(B B)$ for dominant, $1(\mathrm{AA})$ versus $0(\mathrm{AB}+\mathrm{BB})$ for recessive, $0(\mathrm{AA})$ versus $1(\mathrm{BB})$ for additive 1 , and $0(\mathrm{AB})$ versus $1(\mathrm{BB})$ for additive2 (A: minor allele; $\mathrm{B}$ : major allele).

\section{ACKNOWLEDGMENTS}

We thank the participating long-lived individuals and research staff at the Sichuan Provincial People's Hospital for their assistance and support for this project.

\section{CONFLICTS OF INTEREST} interests.

All of authors declare that they have no competing

\section{FUNDING}

This work was supported by the Natural Science Foundation of China (no. 81470667 to .D.D.Z.).

\section{REFERENCES}

1. Terry DF, Sebastiani P, Andersen SL and Perls TT. Disentangling the roles of disability and morbidity in survival to exceptional old age. Archives of internal medicine. 2008; 168:277-283.

2. van der Horst A and Burgering BM. Stressing the role 
of FoxO proteins in lifespan and disease. Nature reviews Molecular cell biology. 2007; 8:440-450.

3. de Candia P, Blekhman R, Chabot AE, Oshlack A and Gilad Y. A combination of genomic approaches reveals the role of FOXO1a in regulating an oxidative stress response pathway. PLoS One. 2008; 3:e1670.

4. Chung WH, Dao RL, Chen LK and Hung SI. The role of genetic variants in human longevity. Ageing research reviews. 2010; 9 Suppl 1:S67-78.

5. Kojima T, Kamei H, Aizu T, Arai Y, Takayama M, Nakazawa S, Ebihara Y, Inagaki H, Masui Y, Gondo Y, Sakaki Y and Hirose N. Association analysis between longevity in the Japanese population and polymorphic variants of genes involved in insulin and insulin-like growth factor 1 signaling pathways. Experimental gerontology. 2004; 39:1595-1598.

6. Willcox BJ, Donlon TA, He Q, Chen R, Grove JS, Yano $\mathrm{K}$, Masaki KH, Willcox DC, Rodriguez B and Curb JD. FOXO3A genotype is strongly associated with human longevity. Proceedings of the National Academy of Sciences of the United States of America. 2008; 105:1398713992.

7. Li Y, Wang WJ, Cao H, Lu J, Wu C, Hu FY, Guo J, Zhao L, Yang F, Zhang YX, Li W, Zheng GY, Cui H, Chen X, Zhu Z, He H, et al. Genetic association of FOXO1A and FOXO3A with longevity trait in Han Chinese populations. Human molecular genetics. 2009; 18:4897-4904.

8. Anselmi CV, Malovini A, Roncarati R, Novelli V, Villa F, Condorelli G, Bellazzi R and Puca AA. Association of the FOXO3A locus with extreme longevity in a southern Italian centenarian study. Rejuvenation research. 2009; 12:95-104.

9. Soerensen M, Dato S, Christensen K, McGue M, Stevnsner $\mathrm{T}$, Bohr VA and Christiansen L. Replication of an association of variation in the FOXO3A gene with human longevity using both case-control and longitudinal data. Aging cell. 2010; 9:1010-1017.

10. Flachsbart F, Moller M, Daumer C, Gentschew L, Kleindorp R, Krawczak M, Caliebe A, Schreiber S and Nebel A. Genetic investigation of FOXO3A requires special attention due to sequence homology with FOXO3B. European journal of human genetics : EJHG. 2013; 21:240242.

11. Nygaard M, Lindahl-Jacobsen R, Soerensen M, MengelFrom J, Andersen-Ranberg K, Jeune B, Vaupel JW, Tan Q, Christiansen L and Christensen K. Birth cohort differences in the prevalence of longevity-associated variants in APOE and FOXO3A in Danish long-lived individuals. Experimental gerontology. 2014; 57:41-46.

12. Pawlikowska L, Hu D, Huntsman S, Sung A, Chu C, Chen J, Joyner AH, Schork NJ, Hsueh WC, Reiner AP, Psaty BM, Atzmon G, Barzilai N, Cummings SR, Browner WS, Kwok PY, et al. Association of common genetic variation in the insulin/IGF1 signaling pathway with human longevity. Aging cell. 2009; 8:460-472.
13. Flachsbart F, Caliebe A, Kleindorp R, Blanche H, von Eller-Eberstein H, Nikolaus S, Schreiber S and Nebel A. Association of FOXO3A variation with human longevity confirmed in German centenarians. Proceedings of the National Academy of Sciences of the United States of America. 2009; 106:2700-2705.

14. Zeng Y, Cheng L, Chen H, Cao H, Hauser ER, Liu Y, Xiao Z, Tan Q, Tian XL and Vaupel JW. Effects of FOXO genotypes on longevity: a biodemographic analysis. The journals of gerontology Series A, Biological sciences and medical sciences. 2010; 65:1285-1299.

15. Furuyama T, Kitayama K, Shimoda Y, Ogawa M, Sone K, Yoshida-Araki K, Hisatsune H, Nishikawa S, Nakayama K, Nakayama K, Ikeda K, Motoyama N and Mori N. Abnormal angiogenesis in Foxo1 (Fkhr)-deficient mice. The Journal of biological chemistry. 2004; 279:34741-34749.

16. Nygaard M, Soerensen M, Flachsbart F, Mengel-From J, Tan Q, Schreiber S, Nebel A, Christensen K and Christiansen L. AKT1 fails to replicate as a longevityassociated gene in Danish and German nonagenarians and centenarians. European journal of human genetics : EJHG. 2013; 21:574-577.

17. Suh Y, Atzmon G, Cho MO, Hwang D, Liu B, Leahy DJ, Barzilai $\mathrm{N}$ and Cohen P. Functionally significant insulinlike growth factor I receptor mutations in centenarians. Proceedings of the National Academy of Sciences of the United States of America. 2008; 105:3438-3442.

18. Soerensen M, Dato S, Tan Q, Thinggaard M, Kleindorp R, Beekman M, Jacobsen R, Suchiman HE, de Craen AJ, Westendorp RG, Schreiber S, Stevnsner T, Bohr VA, Slagboom PE, Nebel A, Vaupel JW, et al. Human longevity and variation in $\mathrm{GH} / \mathrm{IGF}-1$ /insulin signaling, DNA damage signaling and repair and pro/antioxidant pathway genes: cross sectional and longitudinal studies. Experimental gerontology. 2012; 47:379-387.

19. Turdi S, Li Q, Lopez FL and Ren J. Catalase alleviates cardiomyocyte dysfunction in diabetes: role of Akt, Forkhead transcriptional factor and silent information regulator 2. Life sciences. 2007; 81:895-905.

20. Barthel A, Schmoll D and Unterman TG. FoxO proteins in insulin action and metabolism. Trends in endocrinology and metabolism: TEM. 2005; 16:183-189.

21. Soerensen M, Nygaard M, Dato S, Stevnsner T, Bohr VA, Christensen K and Christiansen L. Association study of FOXO3A SNPs and aging phenotypes in Danish oldest-old individuals. Aging cell. 2015; 14:60-66.

22. Xu Y, Wang L, He J, Bi Y, Li M, Wang T, Wang L, Jiang Y, Dai M, Lu J, Xu M, Li Y, Hu N, Li J, Mi S, Chen CS, et al. Prevalence and control of diabetes in Chinese adults. Jama. 2013; 310:948-959.

23. Karafet TM, Mendez FL, Meilerman MB, Underhill PA, Zegura SL and Hammer MF. New binary polymorphisms reshape and increase resolution of the human $\mathrm{Y}$ chromosomal haplogroup tree. Genome research. 2008; 18:830-838 
24. Tan Q, Soerensen M, Kruse TA, Christensen K and Christiansen L. A novel permutation test for case-only analysis identifies epistatic effects on human longevity in the FOXO gene family. Aging cell. 2013; 12:690-694.

25. Sato Y, Shinka T, Iwamoto T, Yamauchi A and Nakahori Y. $\mathrm{Y}$ chromosome haplogroup $\mathrm{d} 2 *$ lineage is associated with azoospermia in Japanese males. Biology of reproduction. 2013; 88:107.

26. Deelen J, Uh HW, Monajemi R, van Heemst D, Thijssen PE, Bohringer S, van den Akker EB, de Craen AJ, Rivadeneira F, Uitterlinden AG, Westendorp RG, Goeman JJ, Slagboom PE, Houwing-Duistermaat JJ and Beekman M. Gene set analysis of GWAS data for human longevity highlights the relevance of the insulin/IGF-1 signaling and telomere maintenance pathways. Age. 2013; 35:235-249.

27. Relling DP, Esberg LB, Fang CX, Johnson WT, Murphy EJ, Carlson EC, Saari JT and Ren J. High-fat diet-induced juvenile obesity leads to cardiomyocyte dysfunction and upregulation of Foxo3a transcription factor independent of lipotoxicity and apoptosis. Journal of hypertension. 2006; 24:549-561.

28. Christensen K, McGue M, Petersen I, Jeune B and Vaupel JW. Exceptional longevity does not result in excessive levels of disability. Proceedings of the National Academy of Sciences of the United States of America. 2008; 105:1327413279.

29. Roglic G and Unwin N. Mortality attributable to diabetes: estimates for the year 2010. Diabetes research and clinical practice. 2010; 87:15-19.

30. American Diabetes A. Diagnosis and classification of diabetes mellitus. Diabetes care. 2010; 33 Suppl 1:S62-69.

31. Nojima A, Yamashita M, Yoshida Y, Shimizu I, Ichimiya H, Kamimura N, Kobayashi Y, Ohta S, Ishii N and Minamino T. Haploinsufficiency of aktl prolongs the lifespan of mice. PLoS One. 2013; 8:e69178.

32. King DC, Taylor J, Elnitski L, Chiaromonte F, Miller W and Hardison RC. Evaluation of regulatory potential and conservation scores for detecting cis-regulatory modules in aligned mammalian genome sequences. Genome research. 2005; 15:1051-1060.

33. Xu GL, Bestor TH, Bourc'his D, Hsieh CL, Tommerup N, Bugge M, Hulten M, Qu X, Russo JJ and Viegas-Pequignot E. Chromosome instability and immunodeficiency syndrome caused by mutations in a DNA methyltransferase gene. Nature. 1999; 402:187-191.

34. Casillas MA, Jr., Lopatina N, Andrews LG and Tollefsbol TO. Transcriptional control of the DNA methyltransferases is altered in aging and neoplastically-transformed human fibroblasts. Molecular and cellular biochemistry. 2003; 252:33-43.

35. Lopatina N, Haskell JF, Andrews LG, Poole JC, Saldanha $\mathrm{S}$ and Tollefsbol T. Differential maintenance and de novo methylating activity by three DNA methyltransferases in aging and immortalized fibroblasts. Journal of cellular biochemistry. 2002; 84:324-334.

36. Scalera A and Tarantino G. Could metabolic syndrome lead to hepatocarcinoma via non-alcoholic fatty liver disease? World journal of gastroenterology : WJG. 2014; 20:92179228 . 